\title{
EXISTENCE, LOCALIZATION AND MULTIPLICITY OF POSITIVE SOLUTIONS FOR THE DIRICHLET BVP WITH $\phi$-LAPLACIAN
}

\author{
DIANA-RALUCA HERLEA \\ Babeş-Bolyai University, Faculty of Mathematics and Computer Science \\ 1, Kogălniceanu Street, 400084 Cluj-Napoca, Romania \\ E-mail: dherlea@math.ubbcluj.ro
}

\begin{abstract}
The aim of this paper is to discuss the existence, localization and multiplicity of positive solutions for the Dirichlet boundary value problem with $\phi$-Laplacian. Our approach is based on Krasnosel'skil's fixed point theorem in cones and on a weak Harnack type inequality. As concerns the systems, the localization is established by the vector version of Krasnosel'skin's theorem, where the compression-expansion conditions are expressed on components.
\end{abstract}

Key Words and Phrases: Positive solution, $\phi$-Laplacian, boundary value problem, Krasnosel'ski1's fixed point theorem in cones, weak Harnack inequality.

2010 Mathematics Subject Classification: 34B18, 47H10.

Acknowledgements. This paper is a result of a doctoral research made possible by the financial support of the Sectoral Operational Programme for Human Resources Development 2007-2013, co-financed by the European Social Fund, under the project POSDRU/159/1.5/S/137750 - "Doctoral and postdoctoral programs - support for increasing research competitiveness in the field of exact Sciences".

\section{REFERENCES}

[1] A. Benmezaï, S. Djebali, T. Moussaoui, Positive solutions for $\phi$-Laplacian Dirichlet BVPs, Fixed Point Theory, 8(2007), 167-186.

[2] A. Benmezaï, S. Djebali, T. Moussaoui, Multiple positive solutions for $\phi$-Laplacian Dirichlet BVPs, Panamer. Math. J., 17(2007), 53-73.

[3] C. Bereanu, J. Mawhin, Boundary value problems for some nonlinear systems with singular $\phi$-laplacian, J. Fixed Point Theory Appl., 4(2008), 57-75.

[4] C. Bereanu, J. Mawhin, Nonhomogeneous boundary value problems for some nonlinear equations with singular $\phi$-Laplacian, J. Math. Anal. Appl., 352(2009), 218-233.

[5] A. Cabada, R.L. Pouso, Existence results for the problem $\left(\phi\left(u^{\prime}\right)\right)^{\prime}=f\left(t, u, u^{\prime}\right)$ with nonlinear boundary conditions, Nonlinear Anal., 35(1999), 221-231.

[6] S.-S. Chen, Z.-H. Ma, The solvability of nonhomogeneous boundary value problems with $\phi-$ Laplacian operator, Bound. Value Probl. 2014, doi:10.1186/1687-2770-2014-82.

[7] M. García-Huidobro, P. Ubilla, Multiplicity of solutions for a class of nonlinear second-order equations, Nonlinear Anal., 28(1997), 1509-1520.

[8] S. Heikkila, S. Seikkala, Maximum principles and uniqueness results for phi-Laplacian boundary value problems, J. Inequal. Appl., 6(2001), 339-357. 
[9] D.-R. Herlea, Existence and localization of positive solutions to first order differential systems with nonlocal conditions, Studia Univ. Babeş-Bolyai, Math., 59(2014), 221-231.

[10] D.-R. Herlea, R. Precup, Existence, localization and multiplicity of positive solutions to $\phi$ Laplace equations and systems, submitted.

[11] M.A. Krasnosel'skiı̌, Positive Solutions of Operator Equations, Noordhoff, Groningen, 1964.

[12] J. Mawhin, Boundary value problems for nonlinear perturbations of some $\phi$-Laplacians, Banach Center Publ., 77(2007), 201-214.

[13] R. Precup, A vector version of Krasnosel'skiu's fixed point theorem in cones and positive periodic solutions on nonlinear systems, J. Fixed Point Theory Appl., 2(2007), 141-151.

[14] R. Precup, Componentwise compression-expansion conditions for systems of nonlinear operator equations and applications, in: Mathematical Models in Engineering, Biology and Medicine, AIP Conf. Proc., 1124, Amer. Inst. Phys., Melville, NY, 2009, 284-293.

[15] R. Precup, Abstract week Harnack inequality, multiple fixed points and $p$-Laplace equations, J. Fixed Point Theory Appl., 12(2012), 193-206.

[16] R. Precup, Moser-Harnack inequality, Krasnosel'skiı type fixed point theorems in cones and elliptic problems, Topol. Meth. Nonlinear Anal., 40(2012), 301-313.

Received: March 27, 2015; Accepted: October 8, 2015. 
